\title{
Carbon-Oxygen Bond Formation via Organometallic Baeyer-Villiger Transformations: A Computational Study on the Impact of Metal Identity
}

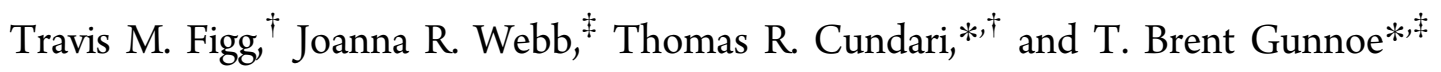

${ }^{\dagger}$ Department of Chemistry and Center for Advanced Scientific Computing and Modeling, University of North Texas, 1155 Union Circle, \#305070, Denton, Texas 76203-5017, United States

${ }^{\ddagger}$ Department of Chemistry, University of Virginia, McCormick Road, P.O. Box 400319, Charlottesville, Virginia 22904-4319, United States

\section{Supporting Information}

ABSTRACT: Metal-mediated formation of $\mathrm{C}-\mathrm{O}$ bonds is an important transformation that can occur by a variety of mechanisms. Recent studies suggest that oxygen-atom insertion into metal-hydrocarbyl bonds in a reaction that resembles the Baeyer-Villiger transformation is a viable process. In an effort to identify promising new systems, this study is designed to assess the impact of metal identity on such $\mathrm{O}$-atom insertions for the reaction $\left[(\mathrm{bpy})_{x} \mathrm{M}(\mathrm{Me})(\mathrm{OOH})\right]^{n} \rightarrow\left[(\mathrm{bpy})_{x} \mathrm{M}(\mathrm{OMe})(\mathrm{OH})\right]^{n}(x=1$ or 2 ; bpy $=$ 2,2'-bipyridyl; $n$ is varied to maintain the d-electron count at $\mathrm{d}^{6}$ or $\left.\mathrm{d}^{8}\right)$. Six $\mathrm{d}^{8}$-squareplanar complexes $\left(\mathrm{M}=\mathrm{Pt}^{\mathrm{II}}, \mathrm{Pd}^{\mathrm{II}}, \mathrm{Ni}^{\mathrm{II}}, \mathrm{Ir}^{\mathrm{I}}, \mathrm{Rh}^{\mathrm{I}}\right.$, and $\left.\mathrm{Co}^{\mathrm{I}}\right)$ and eight $\mathrm{d}^{6}$-octahedral systems $\left(\mathrm{M}=\mathrm{Ir}^{\mathrm{III}}, \mathrm{Rh}^{\mathrm{III}}, \mathrm{Co}^{\mathrm{III}}, \mathrm{Fe}^{\mathrm{II}} \mathrm{Ru}^{\mathrm{II}}, \mathrm{Os}^{\mathrm{II}}, \mathrm{Mn}^{\mathrm{I}}\right.$, and $\left.\mathrm{Tc}^{\mathrm{I}}\right)$ are studied. Using density functional theory calculations, the structures and energies of ground-state and transition-state species are elucidated. This study shows clear trends in calculated $\Delta G^{\dagger}$ 's for the O-atom insertions. The organometallic BaeyerVilliger insertions are favored by lower coordination numbers $(x=1$ versus $x=2)$, earlier transition metals, and first-row (3d) transition metals.

\section{INTRODUCTION}

Selective catalysts for the direct partial oxidation of hydrocarbons, especially alkanes, have been a long-standing goal. ${ }^{1-13}$ Several strategies for catalytic $\mathrm{C}-\mathrm{H}$ functionalization have evolved, with the most heavily studied systems including electrophilic late transition metals (e.g., $\mathrm{Pt}, \mathrm{Pd}, \mathrm{Hg}$, and $\mathrm{Au}$ ), ${ }^{1-4,9,14-16}$ highvalent metal-oxo or nitrene systems, ${ }^{17-22}$ and transition metal carbene complexes. ${ }^{23,24}$ Among the more promising catalysts for hydrocarbon partial oxidation are electrophilic late transition metal systems. ${ }^{1-3,9,14,15}$ For example, heating aqueous solutions of $\mathrm{Pt}^{\mathrm{II}}$ salts with hydrocarbons and an external oxidant produces alcohol or alkyl chloride compounds (the Shilov system). ${ }^{1,12,25}$ The most commonly invoked pathway for Shilov catalysts involves initial alkane $\mathrm{C}-\mathrm{H}$ activation to generate a $\mathrm{Pt}^{\mathrm{II}}$-alkyl intermediate, oxidation of the $\mathrm{Pt}^{\mathrm{II}}$-alkyl to produce a $\mathrm{Pt}^{\mathrm{IV}}$-alkyl species, nucleophilic attack by water or chloride on the hydrocarbyl ligand, and dissociation of the functionalized product. Despite numerous studies that have revealed details of this and related systems, ${ }^{4,9,12,16,26}$ several limitations that prevent the implementation of scaled-up processes have not been overcome.

One key goal for the development of catalysts for selective hydrocarbon partial oxidation is the incorporation of inexpensive oxidants that can be regenerated from dioxygen. The original Shilov catalytic system utilized $\mathrm{Pt}^{\mathrm{IV}}$ as the stoichiometric oxidant, ${ }^{25}$ and although examples with other oxidants have been reported (e.g., $\left.\mathrm{H}_{2} \mathrm{SO}_{4}\right),{ }^{3}$ the development of processes that utilize oxidants other than $\mathrm{Pt}^{\mathrm{IV}}$ has been challenging. ${ }^{9,27,28}$
An alternative strategy to Shilov-type catalysis is a process that involves $\mathrm{C}-\mathrm{O}$ bond formation by net oxygen-atom insertion into a $\mathrm{M}-\mathrm{R}$ bond. An example of such a catalytic cycle is shown in Scheme 1, which involves $\mathrm{C}-\mathrm{H}$ activation by $1,2-\mathrm{CH}$ addition across a $\mathrm{M}-\mathrm{OR}$ bond and $\mathrm{O}$-atom insertion into a $\mathrm{M}-\mathrm{R}$ bond as the key steps. ${ }^{5,29-31}$ In Scheme 1, two distinct

Scheme 1. Possible Pathways for $\mathrm{C}-\mathrm{H}$ Functionalization Involving Oxygen-Atom Insertion into a $\mathrm{M}-\mathrm{R}$ Bond and 1,2-CH-Addition across a Metal-Heteroatom Bond

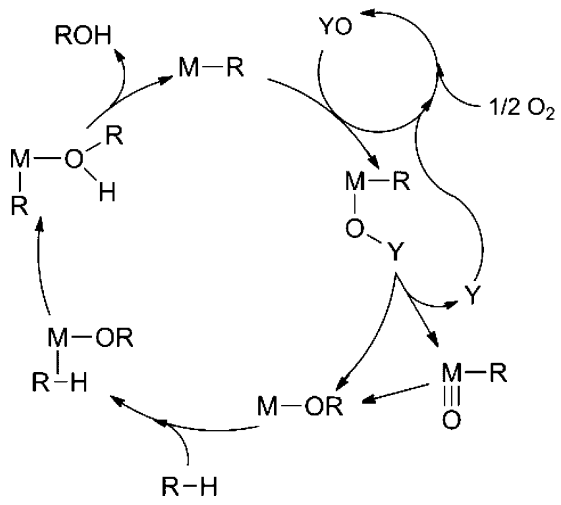

Received: November 1, 2011

Published: December 20, 2011 
pathways for O-atom insertion are shown. One involves the formation of a metal-oxo complex upon dissociation of "Y", which formally oxidizes the metal by two electrons, followed by net migration of the ligand $\mathrm{R}$ to the oxo to produce an alkoxide ligand. Well-defined methyl migration to oxo ligands has only been observed for a few systems, ${ }^{32,33}$ and examples of thermally induced $(\mathrm{R}) \mathrm{M} \equiv \mathrm{O} \rightarrow \mathrm{M}-\mathrm{OR}$ are extremely rare. ${ }^{32}$ As previously discussed, ${ }^{32}$ an inherent challenge to oxo insertion into $\mathrm{M}-\mathrm{R}$ bonds is that metal-hydrocarbyl and metal-oxo bonds are often polarized such that the hydrocarbyl and oxo are both nucleophilic. In fact, Mayer and Brown have suggested that oxo insertion into a $\mathrm{Re}^{\mathrm{VII}}$-phenyl bond is a result of strong oxoto-Re $\pi$-donation, which enhances the electrophilicity of the oxo ligands. A second pathway for $\mathrm{C}-\mathrm{O}$ bond formation in Scheme 1 is direct $\mathrm{O}$-atom insertion and concomitant loss of $\mathrm{Y}$ without prior formation of a metal-oxo complex. Henceforth, this pathway will be referred to as an organometallic Baeyer-Villiger (OMBV) reaction. The OMBV reaction occurs without changing the formal oxidation state of the metal.

Despite the possible utility of metal-mediated $\mathrm{C}-\mathrm{O}$ bondforming reactions, the net insertion of oxygen into metal-alkyl or metal-aryl bonds of middle to late transition metals to give alkoxide or aryloxide ligands has been observed only rarely. Brown and Mayer have reported oxo insertion into $M-R$ bonds with $\mathrm{Re}^{\mathrm{VII}}$ under both thermal and photolytic conditions. ${ }^{32,33}$ Hillhouse et al. have reported examples of $\mathrm{Ni}-\mathrm{C} \rightarrow$ $\mathrm{Ni}-\mathrm{O}-\mathrm{C}$ transformations. ${ }^{34-36}$ For example, the reaction of $\left(\mathrm{PMe}_{3}\right)_{2} \mathrm{Ni}\left(\kappa^{2}-\mathrm{C}, \mathrm{C}-\mathrm{CH}_{2} \mathrm{CMe}_{2}-\mathrm{o}-\mathrm{C}_{6} \mathrm{H}_{4}\right)$ with $\mathrm{N}_{2} \mathrm{O}$ in $\mathrm{C}_{6} \mathrm{D}_{6}$ for 3 days at $55^{\circ} \mathrm{C}$ produces $\left[\left(\mathrm{PMe}_{3}\right) \mathrm{Ni}\left(\kappa^{2}-\mathrm{O}, \mathrm{C}-\mathrm{O}-o-\mathrm{C}_{6} \mathrm{H}_{4} \mathrm{CMe}_{2}-\right.\right.$ $\left.\left.\mathrm{CH}_{2}\right)\right]_{2}$. Oxygen-atom insertion into $\mathrm{Pd}$-aryl bonds has been reported, ${ }^{37}$ and proposed pathways involve the formation of Pd(IV)-oxo complexes; ${ }^{38}$ however, evidence for the formation of Pd(IV)-oxo systems has not been reported. Espenson et al. reported that the reaction of methyltrioxorhenium (MTO) with oxidants generates methanol. ${ }^{39}$ Recently, Periana, Goddard, et al. reported that the reaction of MTO with 2 equiv of external oxidant (e.g., $\mathrm{PhIO}, \mathrm{H}_{2} \mathrm{O}_{2}$, and $\mathrm{IO}_{4}^{-}$) in $\mathrm{D}_{2} \mathrm{O}$ at $25^{\circ} \mathrm{C}$ for $1 \mathrm{~h}$ generates methanol. The conversion of external oxidants and the $\mathrm{Re}-\mathrm{Me}$ bond of MTO to a methoxide ligand does not involve the migration of a methyl group to an oxo ligand. ${ }^{29,40}$ Rather, an OMBV pathway was proposed with a calculated activation barrier of $17 \mathrm{kcal} / \mathrm{mol}$ for $\mathrm{IO}_{4}^{-}$(Scheme 2). Application of this reaction

Scheme 2. Organometallic Baeyer-Villiger Transition State for Oxygen-Atom Insertion into the $\mathrm{Re}-\mathrm{Me}$ Bond of Methyltrioxorhenium (MTO)

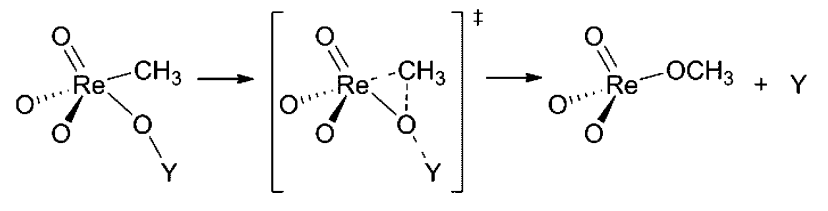

to an analogous $\mathrm{Re}-$ aryl system, $\mathrm{O}_{3} \operatorname{ReAr}(\mathrm{Ar}=$ mesityl), has been demonstrated to proceed through an OMBV pathway to produce the corresponding phenol. ${ }^{41}$

Extension of the OMBV transformation to systems for which the resulting metal-alkoxide (or aryloxide) can activate $\mathrm{C}-\mathrm{H}$ bonds $5,30,31,42-48$ offers the opportunity to develop catalytic processes for the direct conversion of hydrocarbons to alcohols. The $\mathrm{Re}^{\mathrm{VII}}$ methoxide complex $\mathrm{O}_{3} \mathrm{Re}(\mathrm{OMe})$, which forms from MTO and $\mathrm{YO}\left(\mathrm{Y}=\mathrm{HO}^{-}\right.$, pyridine, $\left.\mathrm{IO}_{3}^{-}, \mathrm{PhI}\right)$, is insufficiently reactive to activate $\mathrm{C}-\mathrm{H}$ bonds, and this is likely a common feature of $\mathrm{d}^{0} \mathrm{M}-\mathrm{OMe}$ complexes. Thus, completion of the catalytic cycle shown in Scheme 1 would likely require access to the OMBV transformation with more d-electron-rich metals. However, the features of the metal that facilitate the OMBV reaction are not well understood. For example, $\mathrm{Re}^{\mathrm{VII}}$ and $\mathrm{Ni}^{\mathrm{II}}$ systems have both been proposed to undergo O-atom insertion via the $\mathrm{OMBV}$ reaction, although they are quite disparate transition-metal complexes. In addition to the experimental studies, we have reported a computational Hammett study based on bipyridyl-Pt ${ }^{\mathrm{II}}$ complexes. ${ }^{49}$ These studies suggested electronic effects similar to the organic BV reaction and indicated that the OMBV reaction with electrophilic late transition metals would have prohibitively high activation barriers. Given the scarcity of well-defined $\mathrm{O}$-atom insertions into $\mathrm{M}-\mathrm{R}$ bonds, we sought to use density functional theory (DFT) to establish trends that could effectively guide future experimental efforts to study and optimize $\mathrm{M}-\mathrm{R} \rightarrow \mathrm{M}-\mathrm{O}-\mathrm{R}$ reactions via the OMBV pathway. In this report, a systematic study was performed to elucidate trends in the OMBV reaction as a function of metal identity and coordination number. We have evaluated the reaction of a series of Group 7-10 four-coordinate $d^{8}$ and sixcoordinate $\mathrm{d}^{6}$ complexes with hydroperoxide as the oxidant. In order to focus on the impact of the metal, the ancillary ligand, 2,2'-bipyridyl (bpy), was held constant for the series of complexes studied. These studies provide distinct trends in $\Delta G^{\ddagger}$ as a function of metal identity and coordination number.

\section{COMPUTATIONAL METHODS}

The Gaussian 09 package ${ }^{50}$ was used to model ground and transition states. Geometry optimization and vibrational frequency calculations were performed at the DFT level, using the hybrid functional B3LYP $\mathrm{P}^{51,52}$ and the Stevens valence basis sets with pseudopotentials and $\mathrm{d}$ functions added to the main-group elements, i.e., CEP-31G(d). ${ }^{53-55}$ The current level of theory was calibrated versus computations reported against the known $\mathrm{OMBV}$ oxidations of $\mathrm{ReO}_{3} \mathrm{Me}$, (i.e., $\left[\mathrm{O}_{3} \mathrm{ReMe}(\mathrm{OOH})\right]^{-} \rightarrow$ $\left.\left[\mathrm{O}_{3} \mathrm{Re}(\mathrm{OH})(\mathrm{OMe})\right]^{-}\right)$, with no appreciable differences. Additionally, calibration of standard double- $\zeta$-plus-polarization valence basis sets (VBSs) against larger triple- $\zeta$-plus-polarization with diffuse functions VBSs $(C E P-121 G+(d))$ did not afford appreciable differences in the calculated geometries and energetics. All minima and transition states were discerned by the presence of 0 or 1 imaginary frequencies, respectively, from the calculated energy Hessians. The current level of theory has been used in a previous study of OMBV-mediated oxidation, ${ }^{49}$ among many other analyses of organometallic catalysis, and will be used in this study to compare/contrast complexes of Group 7, 8, 9, and 10 metals of varying coordination number and d-electron count.

The free energies of activation are calculated at standard conditions $(1 \mathrm{~atm}, 298.15 \mathrm{~K})$ for the respective OMBV transition states, and for each metal/ligand combination the free energies are reported relative to the adduct formed by coordination of hydroperoxide, which we have termed the metallo-Criegee intermediate (MCI), $\left[(\text { bpy })_{x} \mathrm{M}(\mathrm{Me})(\mathrm{OOH})\right]^{n}$ $\left(x=1\right.$ for four-coordinate, $\mathrm{d}^{8}$-square-planar systems; $x=2$ for sixcoordinate, $\mathrm{d}^{6}$-octahedral systems). Different spin states for the $3 \mathrm{~d}$ metal systems were evaluated; $4 \mathrm{~d}$ and $5 \mathrm{~d}$ systems are assumed to be in the lowest singlet spin state. Most of the MCIs and the alkoxide products have the same spin state. Exceptions include the $\mathrm{Fe}^{\mathrm{II}}$ complex, where the $\mathrm{MCI}$ is a quintet and the alkoxide product is a singlet, and the $\mathrm{Co}^{\mathrm{I}}$ and $\mathrm{Co}^{\mathrm{III}}$ complexes, which exhibit spin crossover in the OMBV transition state.

Solvation was modeled using the conductor-like Polarization Continuum Model $(\mathrm{CPCM})^{56}$ with THF as the model solvent. However, no substantial impact on the thermodynamics and kinetics was observed for the OMBV pathways. The present results incorporating solvent are complemented by those seen previously for another known OMBV system, MTO $\left(\mathrm{O}_{3} \mathrm{ReMe}\right)$, where incorporation of continuum 
solvent effects had only a minimal impact on the barrier to oxy insertion. ${ }^{29}$

\section{RESULTS}

Oxygen-Atom Insertion Reactions with $d^{8}$-SquarePlanar Complexes. We begin with four-coordinate $\mathrm{d}^{8}$ precursors of the type $[(\mathrm{bpy}) \mathrm{M}(\mathrm{OOH})(\mathrm{Me})]^{n}$ (bpy $=2,2^{\prime}$ bipyridyl) for which the overall charge $n$ is varied to maintain a $\mathrm{d}^{8}$ electron count. The OMBV reaction is shown in Scheme 3.

Scheme 3. Calculated Reaction Pathway for an OMBV Transformation Starting from a Four-Coordinate, SquarePlanar System ${ }^{a}$

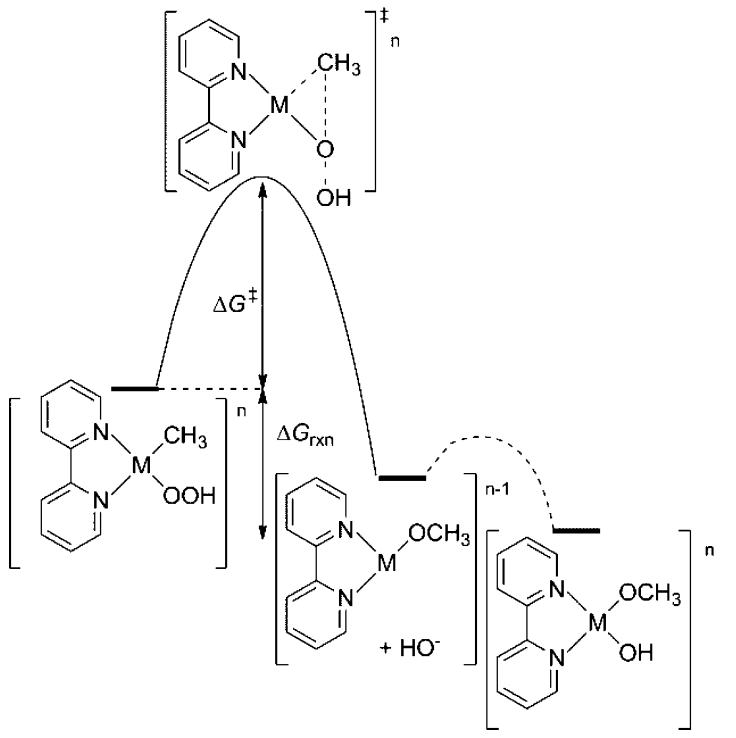

${ }^{a}$ The activation energy of the second step (i.e., coordination of $\mathrm{HO}^{-}$) was assumed to be negligible and was not calculated.

DFT was used to calculate $\Delta G^{\ddagger}$ and $\Delta G_{\mathrm{rxn}}$ for complexes with $\mathrm{M}=\mathrm{Pt}^{\mathrm{II}}, \mathrm{Pd}^{\mathrm{II}}$, or $\mathrm{Ni}^{\mathrm{II}}(n=0)$ and $\mathrm{M}=\mathrm{Ir}^{\mathrm{I}}, \mathrm{Rh}^{\mathrm{I}}$, or $\mathrm{Co}^{\mathrm{I}}(n=-1)$. Attempts to extend the calculations to four-coordinate or sixcoordinate metals another group in either direction (Group 8 or 11 and Group 6 or 10, respectively), while maintaining the $\mathrm{d}^{8}$ or $\mathrm{d}^{6}$ electronic configuration of the metal ion, led to either a non-OMBV transformation or an unstable conformation.

The calculated energetics for oxy insertion of the Group 9 and 10 four-coordinate systems are displayed in Table 1. A few

Table 1. Calculated Energetics ( $\mathrm{kcal} / \mathrm{mol}$ ) for Oxygen-Atom Insertion for $\mathrm{d}^{8}$ Four-Coordinate Group 9 and $\mathbf{1 0}$ Complexes $[(\text { bpy }) \mathrm{M}(\mathrm{OOH})(\mathrm{Me})]^{\mathrm{n}}$

$\begin{array}{cccc}\text { metal } & \text { overall charge }(n) & \Delta G^{+} & \Delta G_{\text {rxn }} \\ \mathrm{Ni}^{\mathrm{II}} & 0 & 39.3 & -67.4 \\ \mathrm{Pd}^{\mathrm{II}} & 0 & 48.6 & -53.2 \\ \mathrm{Pt}^{\mathrm{II}} & 0 & 57.5 & -51.7 \\ \mathrm{Co}^{\mathrm{I}} & 1^{-} & 26.3 & -69.3 \\ \mathrm{Rh}^{\mathrm{I}} & 1^{-} & 35.6 & -61.4 \\ \mathrm{Ir}^{\mathrm{I}} & 1^{-} & 38.6 & -58.6\end{array}$

trends are apparent: (1) The activation barriers for 3d metals are substantially smaller than their $4 \mathrm{~d}$ and $5 \mathrm{~d}$ counterparts. (2) Within a congeneric series, more exergonic insertions lead to lower barriers for the $\mathrm{O}$-atom insertion reaction. (3) The $\Delta G^{\dagger}$ 's for Group 9 complexes have consistently lower $\Delta G^{\ddagger}$ 's than their
Group 10 counterparts. For both Group 9 and 10 systems, with the exception of $\mathrm{Ir}^{\mathrm{I}} \rightarrow \mathrm{Rh}^{\mathrm{I}}$, each change in metal identity $5 \mathrm{~d} \rightarrow$ $4 \mathrm{~d} \rightarrow 3 \mathrm{~d}$ results in a decrease in $\Delta G^{\ddagger}$ of $\sim 9 \mathrm{kcal} / \mathrm{mol}$. The transition from Group 10 to Group 9 results in reductions of calculated $\Delta G^{\dagger}$ 's of $27-33 \%$.

Figure 1 shows the optimized ground-state MCI, [(bpy)M$(\mathrm{Me})(\mathrm{OOH})]^{n}$, and $\mathrm{OMBV}$ transition-state geometries for the calculated $\mathrm{d}^{8}$ four-coordinate complexes. The OMBV transition state is characterized by four coplanar chemical groups in the active site (i.e., methyl, O-atom, metal, and hydroxide). Inspection of the calculated structures reveals some similarities. In all six cases, conversion from the MCI to the OMBV transition state results in an increase in the $\mathrm{M}-\mathrm{OH}$ bond distance. Thus, these 16-electron complexes do not compensate for $\mathrm{O}-\mathrm{O}$ bond cleavage by coordinating the hydroxide moiety during the $\mathrm{O}$-atom insertion into the metal-methyl bond. With the exception of Ir, the $\mathrm{M}-\mathrm{O}$ bond distance of the coordinated oxygen atom decreases by $\sim 0.06-0.1 \AA$ upon conversion to the transition state for the OMBV reaction. In each case, the $\mathrm{C}-\mathrm{O}$ bond distance in the transition state is shorter for the Group 10 complex relative to the Group 9 counterpart by $0.14-0.17 \AA$, which suggests a later transition state for the Group 10 systems. The position of the transition state (i.e., early transition state) appears to correlate with calculated $\Delta G_{\mathrm{rxn}}$, as the Group 10 systems are calculated to be less exothermic than corresponding Group 9 systems in the same row. The $\mathrm{C}-\mathrm{O}$ bond distance in the calculated transition state for $\mathrm{O}$-atom insertion into the $\mathrm{Re}-\mathrm{Me}$ bond of $\mathrm{O}_{3} \mathrm{Re}(\mathrm{Me})(\mathrm{OOH})(2.079 \AA)$ is substantially longer than any $\mathrm{C}-\mathrm{O}$ bond of the systems calculated here. The longer $\mathrm{C}-\mathrm{O}$ bond distance in the MTO transition state is consistent with the calculated lower activation barrier and more exothermic reaction. ${ }^{40}$

The calculated structures for $\mathrm{Pd}$ reveal two distinctions relative to the other five $\mathrm{d}^{8}$ systems. First, in the Pd transition state, the active-site components $\left(\mathrm{Pd}, \mathrm{CH}_{3}, \mathrm{O}\right.$, and $\left.\mathrm{OH}\right)$ are not in the same plane, with a $\mathrm{C}-\mathrm{Pd}-\mathrm{O}-\mathrm{O}$ dihedral angle of $160^{\circ}$ as opposed to a dihedral angle of $\sim 180^{\circ}$ observed for every other four-coordinate OMBV transition state modeled in this research. In addition, the Pd OMBV transition state is closer to a $\kappa^{2}-\mathrm{O}, \mathrm{O}$ conformation, with the hydroxide leaving group of the oxidant at a much shorter distance $(\mathrm{Pd}-\mathrm{OH}=$ $2.68 \AA$ ) than the other OMBV transition states.

Oxygen-Atom Insertion Reactions with Octahedral $d^{6}$ Complexes. The OMBV pathway was also modeled using a series of valence isoelectronic $\mathrm{d}^{6}$ metal complexes of the type $\left[(\text { bpy })_{2} \mathrm{M}(\mathrm{OOH})(\mathrm{Me})\right]^{n}(\mathrm{M}=\mathrm{Co}, \mathrm{Rh}$, or Ir, $n=1 ; \mathrm{M}=\mathrm{Fe}$, $\mathrm{Ru}$, or Os, $n=0$; Mn or Tc, $n=-1$ ) (Scheme 4). The sixcoordinate complexes display trends in $\Delta G^{\dagger}$ that are similar to those for the four-coordinate $\mathrm{d}^{8}$ systems (Table 2). The more exergonic OMBV transformations correlate with smaller activation barriers, and the calculated $\Delta G^{\dagger}$ 's decrease from right to left in a row and from bottom to top in a group. For the Group 9 metals, the calculated OMBV barriers for the $\mathrm{d}^{6}$ sixcoordinate complexes are significantly higher than for the corresponding $\mathrm{d}^{8}$ four-coordinate systems (i.e., four-coordinate $\mathrm{Co}^{\mathrm{I}}, \mathrm{Rh}^{\mathrm{I}}$, and $\left.\mathrm{Ir}^{\mathrm{I}}\right) . \mathrm{Fe}^{\mathrm{II}}$ was calculated to possess a quintet ground state for the MCI and a singlet ground state for the OMBV transition state. $\mathrm{Mn}^{\mathrm{I}}$ was found to be a septet for both stationary points. All other systems were singlets in the MCI ground state.

Figure 2 shows the optimized ground-state MCI and OMBV transition-state geometries for the series of $\mathrm{d}^{6}$ six-coordinate 


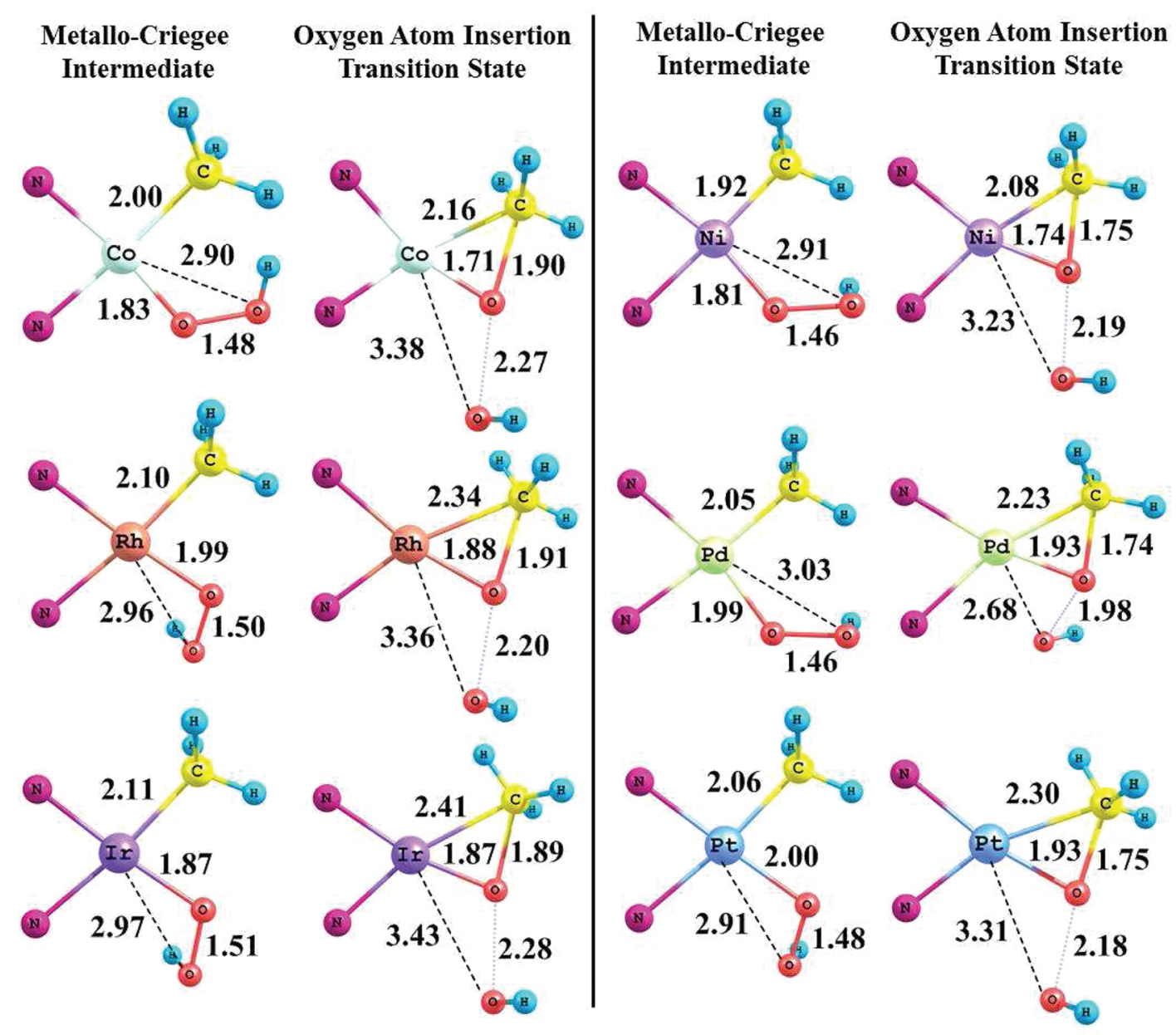

Figure 1. Core geometries for the four-coordinate $\mathrm{Pt}^{\mathrm{II}}, \mathrm{Pd}^{\mathrm{II}}, \mathrm{Ni}^{\mathrm{II}}, \mathrm{Ir}^{\mathrm{I}}, \mathrm{Rh}^{\mathrm{I}}$, and $\mathrm{Co}^{\mathrm{I}}$ metallo-Criegee intermediates and related $\mathrm{OMBV}$ transition states. Bond lengths in $\AA$. Bpy atoms are removed, except for the $\mathrm{N}$ atoms, for clarity.

complexes. Similar to the four-coordinate systems, all the sixcoordinate $\mathrm{OMBV}$ transition states appear to involve a $\kappa^{1}-\mathrm{OOH}$ moiety, as all $\mathrm{M}-\mathrm{O}_{\beta}$ bond distances are $\geq 2.78 \AA$; however, for the six-coordinate complexes the distance between the metal and $\beta$-oxygen in the calculated transition state is only slightly elongated relative to the ground state (the largest $\Delta \mathrm{M}-\mathrm{O}_{\beta}$ bond distance from MCI to transition state is $0.24 \AA$ ), while this change in bond distance is $>0.3 \AA$ for the four-coordinate systems (with the exception of $\mathrm{Pd}$ ). The $\mathrm{C}-\mathrm{O}$ bond distances in the transition state are longest for the Group 7 complexes and shortest for the Group 9 complexes. This trend is consistent with an early transition state since the OMBV reactions for Group 9 systems are calculated to be less exothermic than the corresponding Group 7 and 8 systems in the same row.

\section{DISCUSSION}

The calculated free energies for the OMBV reactions indicate distinct trends. For all complexes, the calculated $\Delta G^{\dagger}$ 's decrease from bottom to top within a group and from right to left within a row. For the four-coordinate precursors, calculated $\Delta G^{\ddagger}$ 's for Group 9 systems are between 13 and $19 \mathrm{kcal} / \mathrm{mol}$ lower than the $\Delta G^{\dagger}$ 's of their Group 10 counterparts. For six-coordinate precursors, the magnitude of the change in $\Delta G^{\dagger}$ on moving to the left in the period is similar to that for the four-coordinate systems. For example, the Group 8 systems all yielded $\Delta G^{\dagger}$ 's that are lower than the calculated barriers for Group 9 systems by $11-15 \mathrm{kcal} / \mathrm{mol}$. In addition, a comparison of fourcoordinate versus six-coordinate Group 9 precursors reveals a consistent trend of lower $\Delta G^{\dagger}$ s for the four-coordinate systems by $\sim 38 \%$.

We sought a rationalization of the trends in $\Delta G^{\dagger}$ revealed by the calculations, which would potentially allow the development of systems designed specifically to mediate the OMBV transformation. A summary of the OMBV barriers, thermodynamics, d-electron count, overall charge, homolytic bond dissociation free energies (BDFEs), and Mulliken charges for the peroxide/methyl transition-metal starting complexes is given in Table 3 , which, along with the calculated $\Delta G^{\ddagger}$ 's, will form the foundation of our discussion.

In a previous computational study of OMBV reactions for $\mathrm{Pt}^{\mathrm{II}}$ systems, correlations among the bond distances in the active site and computed barriers were identified and analyzed to yield a working picture of the transition state for the OMBV transformation. ${ }^{39}$ However, in the present case for a diversity of metal ions and coordination environments, examining the geometries of the four- and six-coordinate species revealed no correlation between the computed barriers and the active-site bond lengths (see Supporting Information for more details). To identify correlations between properties of the precursor complexes and the calculated $\Delta G^{\dagger}$ 's, we plotted the $\Delta G^{\dagger}$ s 
Scheme 4. Calculated Reaction Pathway for an OMBV Transformation through a Six-Coordinate System ${ }^{a}$

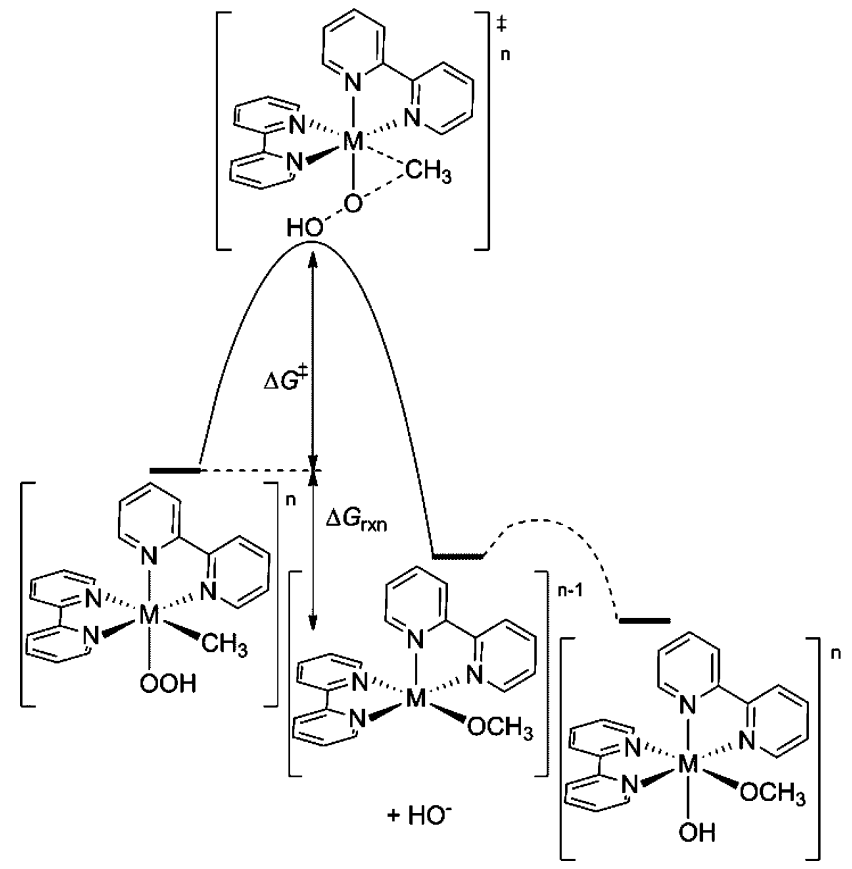

${ }^{a}$ The activation energy of the second step (i.e., coordination of $\mathrm{OH}^{-}$) was assumed to be negligible and was not calculated.

Table 2. Calculated Energetics ( $\mathrm{kcal} / \mathrm{mol}$ ) for Oxygen-Atom Insertion for $\mathrm{d}^{6} \mathrm{Six}-\mathrm{Coordinate}$ Group 7, 8, and 9 Complexes $\left[(\mathrm{bpy})_{2} \mathrm{M}(\mathrm{OOH})(\mathrm{Me})\right]^{n}$

$\begin{array}{lccc}\text { metal } & \text { overall charge } & \Delta G^{+} & \Delta G_{\text {rxn }} \\ \mathrm{Co}^{\mathrm{III}} & 1^{+} & 41.8 & -61.8 \\ \mathrm{Rh}^{\mathrm{III}} & 1^{+} & 54.7 & -51.7 \\ \mathrm{Ir}^{\mathrm{III}} & 1^{+} & 61.8 & -50.1 \\ \mathrm{Fe}^{\mathrm{II}} & 0 & 29.0 & -71.0 \\ \mathrm{Ru}^{\mathrm{II}} & 0 & 43.3 & -60.4 \\ \mathrm{Os}^{\mathrm{II}} & 0 & 46.5 & -60.1 \\ \mathrm{Mn}^{\mathrm{I}} & 1^{-} & 22.6 & -71.2 \\ \mathrm{Tc}^{\mathrm{I}} & 1^{-} & 29.0 & -67.2\end{array}$

versus $\Delta G_{\mathrm{rxn}}$ 's, the calculated metal-methyl and metal-oxygen BDFEs, Pauling electronegativities for the metals, and the Mulliken charges for the metals and the carbon of the migrating methyl group.

A reasonable linear correlation is found for the plot of the $\Delta G^{\ddagger}$ 's and the $\Delta G_{\mathrm{rxn}}$ 's (Figure 3). The more exergonic the overall reaction, the lower the activation barriers for the systems discussed. In order to better understand this trend, we looked for correlations between the calculated $\Delta G^{\dagger}$ 's and the strengths of $\mathrm{M}-\mathrm{CH}_{3}$ and $\mathrm{M}-\mathrm{O}$ bonds by plotting the calculated $\mathrm{M}-\mathrm{CH}_{3}$ and $\mathrm{M}-\mathrm{O}$ BDFEs versus $\Delta G^{\dagger}$ s. Bond strengths for $\mathrm{M}-\mathrm{CH}_{3}$ were determined by calculating the BDFEs for each system under study (eq 1). Bond strengths for $\mathrm{M}-\mathrm{O}$ were measured by calculating the BDFEs for each system (eq 2). The plot of $\mathrm{M}-\mathrm{CH}_{3}$ BDFEs against the OMBV barriers gives a reasonable correlation $\left(R^{2} \approx 0.73\right)$, which shows that weaker $\mathrm{M}-\mathrm{CH}_{3}$ bonds tend to yield lower activation barriers (Figure 4). In contrast, plotting the $\mathrm{M}-\mathrm{O}$ BDFE versus OMBV barriers reveals little correlation $\left(R^{2} \sim 0.39\right)$ (see Supporting
Information for more details), suggesting that $\mathrm{M}-\mathrm{C}$ bond strengths are a more significant determinant of activation barriers for the OMBV transformation than $\mathrm{M}-\mathrm{O}$ bond strengths.

$$
\begin{aligned}
& {\left[(\text { bpy })_{x} \mathrm{M}\left(\mathrm{CH}_{3}\right)(\mathrm{OOH})\right]^{n}} \\
& \quad \rightarrow\left[(\text { bpy })_{x} \mathrm{M}(\mathrm{OOH})\right]^{n}+{ }^{\bullet} \mathrm{CH}_{3} \\
& \quad\left[(\mathrm{bpy})_{x} \mathrm{M}\left(\mathrm{OCH}_{3}\right)(\mathrm{OOH})\right]^{n} \\
& \quad \rightarrow\left[(\mathrm{bpy})_{x} \mathrm{M}(\mathrm{OOH})\right]^{n}+{ }^{\bullet} \mathrm{OCH}_{3}
\end{aligned}
$$

The Mulliken charges of the metal and carbon of the methyl group were calculated for the MCI (Table 3), and we plotted $\Delta G^{\dagger}$ 's as a function of these charges. While there is weak correlation between the charges on the metals and the OMBV activation barriers $\left(R^{2}=0.38\right.$, see Supporting Information), there exists a reasonable correlation $\left(R^{2}=0.65\right)$ between the calculated Mulliken charge on the carbon of the migrating methyl group in the MCI and the OMBV barriers (Figure 5). Much like the OMBV transformations, organic BV systems show a strong connection between the nature of the migrating group and the activation barriers for the oxidation reactions. ${ }^{57-59}$ Thus, the correlation in Figure 5 suggests that increasing the nucleophilicity of the migrating carbon results in lower activation barriers for the OMBV transformations, while the influence of the metal's charge in the MCI ground state is less predictable. To further probe the nature of the OMBV reaction, the charges for the carbon of the methyl groups, the metal, and the coordinated oxygen were calculated for the OMBV transition states. There exists a correlation between the Mulliken charges on the methyl carbon in OMBV transition state and the barriers $\left(R^{2}=0.60\right)$ (Figure 6) as was seen for the MCI ground state. The calculated charges suggest a reduction in the negative charge of the methyl carbon during the OMBV transition state as the methyl group migrates and transfers negative charge to the oxygen atom ligated to the metal center (Table 4). There is no obvious linear correlation between the Pauling electronegativities of the various metals and the OMBV barriers $\left(R^{2}=0.22\right.$ for four-coordinate systems and $R^{2}=0.06$ for six-coordinate systems, see Supporting Information); therefore, for the series of $\left[(\mathrm{bpy})_{x} \mathrm{M}(\mathrm{Me})(\mathrm{OOH})\right]^{n}$ complexes studied herein, a higher degree of electropositive nature for the metal, at least insofar as measured by the Pauling electronegativity, does not correlate with lower OMBV activation barriers. The overall charge of the complex could also affect the activation barriers in OMBV transformations. This is evident when comparing the anionic systems, which afford lower barriers, to the neutral and cationic systems. The lower barriers could be attributed to improving the "leaving group" conditions for the anionic $\mathrm{OH}^{-}$species.

The high spin state for $\mathrm{Mn}^{\mathrm{I}}$ is about $40 \mathrm{kcal} / \mathrm{mol}$ lower in energy than the low spin state for both the MCI and the corresponding OMBV transition state. Therefore, the activation barrier for $\mathrm{O}$-atom insertion is essentially the same for high and low spin states of $\mathrm{Mn}^{\mathrm{I}}$. The $\mathrm{Fe}^{\mathrm{II}}$ complex entails a spin flip from the quintet MCI ground state to a singlet in the OMBV transition state. Unlike the $\mathrm{Mn}^{\mathrm{I}}$ complex, there is a noticeable impact calculated for the spin-conserved barriers. For the $\mathrm{O}$-atom insertion from low-spin $\mathrm{Fe}^{\mathrm{II}}$ to the low-spin transition state, ${ }^{1} \mathrm{MCI} \rightarrow{ }^{1} \mathrm{OMBV}$ transition state, the calculated $\Delta G^{\dagger}$ is $\sim 21 \mathrm{kcal} / \mathrm{mol}$, which is $\sim 8 \mathrm{kcal} / \mathrm{mol}$ lower than for the quintet ground state converting to the low-spin transition state. 

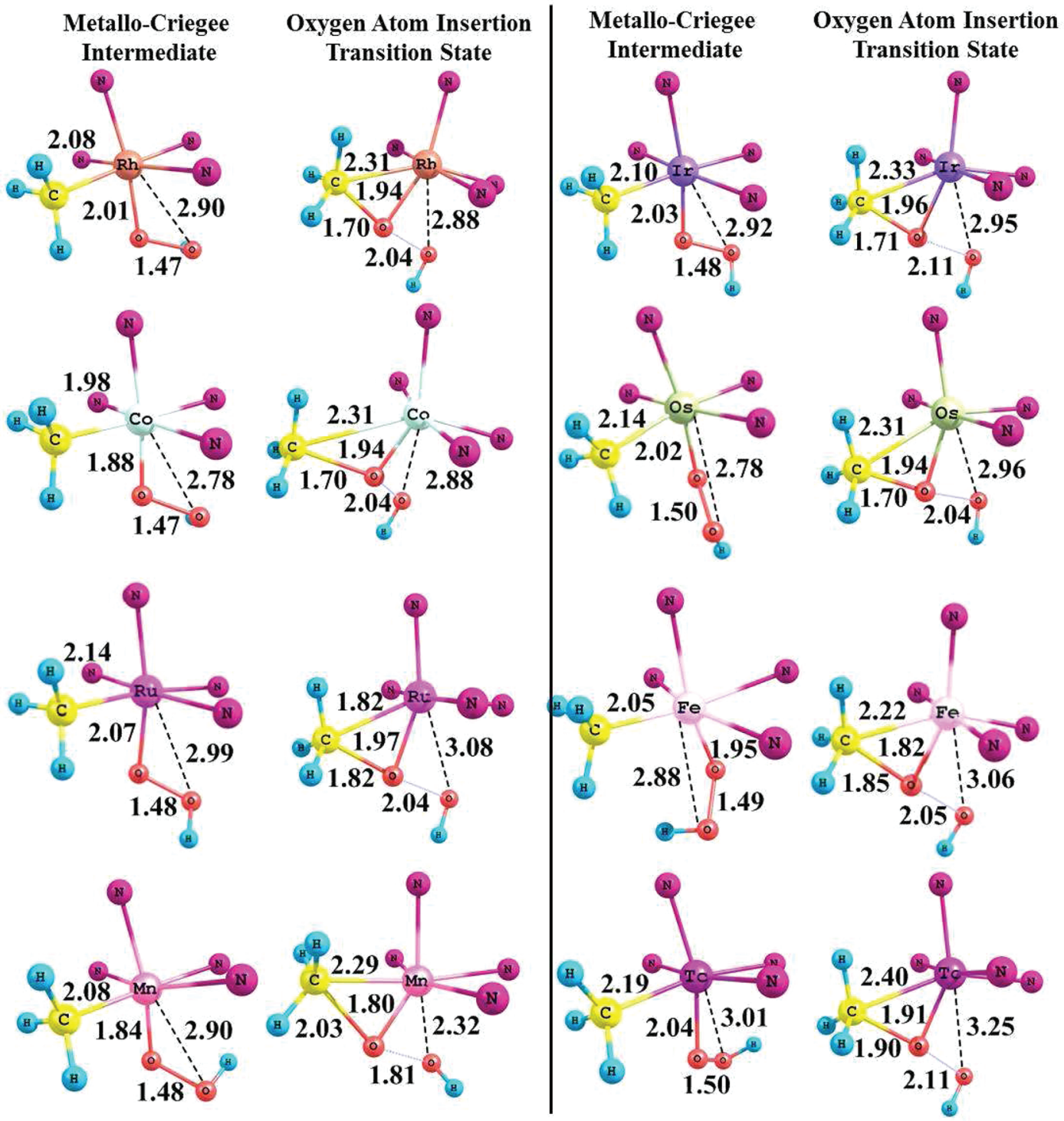

Figure 2. Core geometries for the six-coordinate $\mathrm{Rh}^{\mathrm{III}}, \mathrm{Co}^{\mathrm{III}}, \mathrm{Ir}^{\mathrm{III}}, \mathrm{Fe}^{\mathrm{II}}, \mathrm{Ru}^{\mathrm{II}}, \mathrm{Os}^{\mathrm{II}}, \mathrm{Mn}^{\mathrm{I}}$, and $\mathrm{Tc}^{\mathrm{I}}$ metallo-Criegee intermediates and related $\mathrm{OMBV}$ transition states. Bond lengths in Å. Bpy atoms are removed, except for the $\mathrm{N}$ atoms, for clarity.

Table 3. Summary of Calculated Energetics, d-Electron Count, and Atomic Charges for Carbon and Metal Atoms of MCI for Four- and Six-Coordinate Group 7, 8, and 9 Complexes ${ }^{a}$

\begin{tabular}{|c|c|c|c|c|c|c|c|c|}
\hline metal & d-electron count & overall charge & metal charge & carbon charge & $\mathrm{M}-\mathrm{C}$ BDFE & M-O BDFE & $\Delta G^{+}$ & $\Delta G_{\mathrm{rxn}}$ \\
\hline $\mathrm{Ni}^{\mathrm{II}}$ & 8 & 0 & -0.025 & -0.577 & 18.8 & 37.9 & 39.3 & -67.4 \\
\hline $\mathrm{Pd}^{\mathrm{II}}$ & 8 & 0 & +0.036 & -0.518 & 32.0 & 40.3 & 48.6 & -53.2 \\
\hline $\mathrm{Pt}^{\mathrm{II}}$ & 8 & 0 & -0.022 & -0.467 & 47.5 & 52.2 & 57.5 & -51.7 \\
\hline $\mathrm{Co}^{\mathrm{I}}$ & 8 & $1^{-}$ & +0.147 & -0.759 & 9.3 & 30.8 & 26.3 & -69.3 \\
\hline $\mathrm{Rh}^{\mathrm{I}}$ & 8 & $1^{-}$ & -0.115 & -0.641 & 32.9 & 51.0 & 35.6 & -61.4 \\
\hline $\operatorname{Ir}^{\mathrm{I}}$ & 8 & $1^{-}$ & -0.217 & -0.536 & 39.9 & 54.5 & 38.6 & -58.6 \\
\hline $\mathrm{Co}^{\mathrm{III}}$ & 6 & $1^{+}$ & -0.567 & -0.468 & -0.1 & 14.3 & 41.8 & -61.8 \\
\hline $\mathrm{Rh}^{\mathrm{III}}$ & 6 & $1^{+}$ & -0.415 & -0.400 & 29.3 & 34.4 & 54.7 & -51.7 \\
\hline $\mathrm{Ir}^{\mathrm{III}}$ & 6 & $1^{+}$ & -0.838 & -0.260 & 42.7 & 45.9 & 61.8 & -50.1 \\
\hline $\mathrm{Fe}^{\mathrm{II}}$ & 6 & 0 & +0.173 & -0.720 & 1.4 & 18.3 & 29.0 & -71.0 \\
\hline $\mathrm{Ru}^{\mathrm{II}}$ & 6 & 0 & -0.478 & -0.431 & 30.1 & 44.5 & 43.3 & -60.4 \\
\hline Os ${ }^{I I}$ & 6 & 0 & -0.847 & -0.369 & 34.7 & 48.3 & 46.5 & -60.1 \\
\hline $\mathrm{Mn}^{\mathrm{I}}$ & 6 & $1^{-}$ & +0.163 & -0.546 & 5.4 & 17.5 & 22.6 & -71.2 \\
\hline$T c^{I}$ & 6 & $1^{-}$ & -0.140 & -0.593 & 19.0 & 43.4 & 29.0 & -67.2 \\
\hline
\end{tabular}

${ }^{a}$ All energies given in $\mathrm{kcal} / \mathrm{mol}$; $\mathrm{BDFE}=$ bond dissociation free energy. 


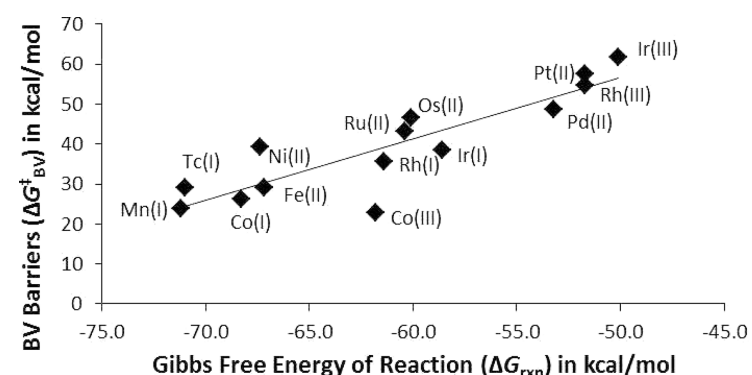

Figure 3. Plot of $\Delta G_{\mathrm{rxn}}, \Delta G^{\ddagger}$ (free energies, $\mathrm{kcal} / \mathrm{mol}$ ) for the OMBV reaction with four- and six-coordinate $\left[(\mathrm{bpy})_{x} \mathrm{M}(\mathrm{Me})(\mathrm{OOH})\right]^{n}$ systems. For each data point, the metal ion and oxidation state are indicated $\left(R^{2}=0.77\right)$

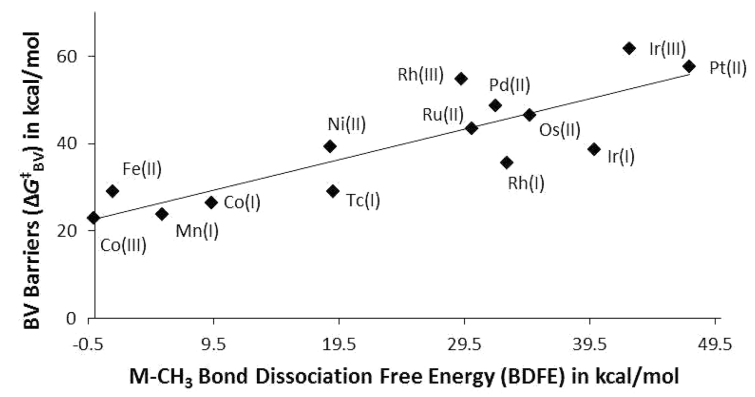

Figure 4. Plot of calculated $\mathrm{M}-\mathrm{CH}_{3}$ BDFE against OMBV activation barriers in $\mathrm{kcal} / \mathrm{mol}\left(R^{2}=0.73\right)$. The metal ion is indicated.

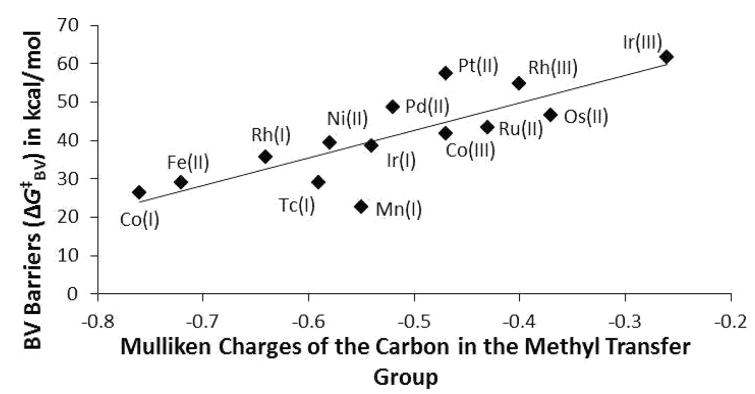

Figure 5. Plot of calculated Mulliken charges on the carbon of the methyl migrating group for four- and six-coordinate metallo-Criegee intermediates and calculated OMBV barriers (free energies, $\mathrm{kcal} / \mathrm{mol}$ ) $\left(R^{2}=0.65\right)$. The central metal ion is indicated.

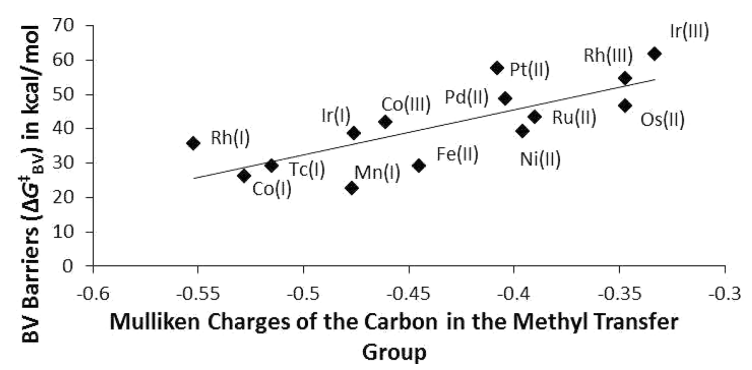

Figure 6. Plot of calculated Mulliken charges on the carbon of the methyl migrating group of the OMBV transition states and calculated barriers (free energies, $\mathrm{kcal} / \mathrm{mol}$ ) for four- and six-coordinate geometries discussed in the text $\left(R^{2}=0.60\right)$. The central metal ion is indicated.

In contrast, the conversion of a quintet ground state to a quintet transition state occurs with a much larger calculated $\Delta G^{\ddagger}$ of $\sim 46 \mathrm{kcal} / \mathrm{mol}$.
Table 4. Summary of Calculated Atomic Charges for Metal, Carbon, and Oxygen of the MCI Ground State and OMBV Transition State for Four- and Six-Coordinate Group 7, 8, and 9 Complexes ${ }^{a}$

\begin{tabular}{|c|c|c|c|c|c|c|}
\hline \multirow[b]{2}{*}{ metal } & \multicolumn{3}{|c|}{ MCI } & \multicolumn{3}{|c|}{ OMBV } \\
\hline & $\begin{array}{l}\text { metal } \\
\text { charge }\end{array}$ & $\begin{array}{l}\text { carbon } \\
\text { charge }\end{array}$ & $\begin{array}{l}\text { oxygen } \\
\text { charge }\end{array}$ & $\begin{array}{l}\text { metal } \\
\text { charge }\end{array}$ & $\begin{array}{l}\text { carbon } \\
\text { charge }\end{array}$ & $\begin{array}{l}\text { oxygen } \\
\text { charge }\end{array}$ \\
\hline $\mathrm{Ni}^{\mathrm{II}}$ & -0.025 & -0.577 & -0.348 & -0.020 & -0.396 & -0.299 \\
\hline $\mathrm{Pd}^{\mathrm{II}}$ & +0.036 & -0.518 & -0.383 & +0.084 & -0.404 & -0.323 \\
\hline $\mathrm{Pt}^{\mathrm{II}}$ & -0.022 & -0.467 & -0.314 & +0.046 & -0.408 & -0.311 \\
\hline $\mathrm{Co}^{\mathrm{I}}$ & +0.147 & -0.759 & -0.358 & -0.087 & -0.528 & -0.303 \\
\hline $\mathrm{Rh}^{\mathrm{I}}$ & -0.115 & -0.641 & -0.339 & -0.086 & -0.552 & -0.325 \\
\hline $\operatorname{Ir}^{\mathrm{I}}$ & -0.217 & -0.536 & -0.310 & -0.124 & -0.476 & -0.314 \\
\hline $\mathrm{Co}^{\mathrm{III}}$ & -0.567 & -0.468 & -0.263 & -0.192 & -0.461 & -0.291 \\
\hline $\mathrm{Rh}^{\mathrm{III}}$ & -0.415 & -0.400 & -0.292 & -0.339 & -0.347 & -0.295 \\
\hline $\mathrm{Ir}^{\mathrm{III}}$ & -0.838 & -0.260 & -0.276 & -0.713 & -0.333 & -0.234 \\
\hline $\mathrm{Fe}^{\mathrm{II}}$ & +0.173 & -0.720 & -0.373 & -0.574 & -0.445 & -0.264 \\
\hline $\mathrm{Ru}^{\mathrm{II}}$ & -0.478 & -0.431 & -0.352 & -0.491 & -0.390 & -0.294 \\
\hline $\mathrm{Os}^{\mathrm{II}}$ & -0.847 & -0.369 & -0.305 & -0.813 & -0.347 & -0.238 \\
\hline $\mathrm{Mn}^{\mathrm{I}}$ & +0.163 & -0.546 & -0.343 & +0.119 & -0.477 & -0.253 \\
\hline $\mathrm{Tc}^{\mathrm{I}}$ & -0.140 & -0.593 & -0.298 & -0.093 & -0.515 & -0.314 \\
\hline
\end{tabular}

\section{SUMMARY AND CONCLUSIONS}

The OMBV reaction provides a route for $\mathrm{C}-\mathrm{O}$ bond formation via $\mathrm{M}-\mathrm{R}+\mathrm{YO} \rightarrow \mathrm{M}-\mathrm{OR}+\mathrm{Y}$. To our knowledge, two examples of this transformation, one with $\mathrm{Re}^{\mathrm{VII}}$ and one with $\mathrm{Ni}^{\mathrm{II}}$, have been suggested. ${ }^{29,34}$ In order to rationally extend this transformation to other complexes and, hence, to potentially incorporate OMBV into catalytic sequences for hydrocarbon functionalization, a better understanding of the factors that control the energetics of the reaction is needed. Within the confines of $\mathrm{d}^{6}$ and $\mathrm{d}^{8}$ complexes, our calculations suggest clear guidelines to optimize systems for the OMBV reaction, including the use of middle transition metals (i.e., earlier metals) in a row (at least to Group 7), first-row metals, and low-coordinate complexes (four- versus six-coordinate). The focus on $\mathrm{d}^{6}$ and $\mathrm{d}^{8}$ complexes is motivated by examples of $\mathrm{Y}-\mathrm{H}(\mathrm{Y}=\mathrm{C}$ or $\mathrm{H})$ activation by $\mathrm{M}-\mathrm{OR}$ systems with these d-electron counts. $^{30,31,42-48,60-62}$ The source of these trends appears to lie in metal-carbon BDFEs and/or charges on the migrating methyl group.

\section{ASSOCIATED CONTENT}

S Supporting Information

Additional correlation plots, Cartesian coordinates of all calculated species, and complete ref 50. This material is available free of charge via the Internet at http://pubs.acs.org.

\section{AUTHOR INFORMATION}

\section{Corresponding Author}

thomas.cundari@unt.edu

\section{ACKNOWLEDGMENTS}

This work was solely supported as part of the Center for Catalytic Hydrocarbon Functionalization, an Energy Frontier Research Center funded by the U.S. Department of Energy, Office of Science, Office of Basic Energy Sciences, under Award No. DE-SC0001298. 


\section{REFERENCES}

(1) Shilov, A. E.; Shulpin, G. B. Russ. Chem. Rev. 1987, 56, 442-464.

(2) Periana, R. A.; Taube, D. J.; Evitt, E. R.; Loffler, D. G.; Wentrcek,

P. R.; Voss, G.; Masuda, T. Science 1993, 259, 340-343.

(3) Periana, R. A.; Taube, D. J.; Gamble, S.; Taube, H.; Satoh, T.;

Fuji, H. Science 1998, 280, 5650.

(4) Labinger, J. A. J. Mol. Catal. A: Chem. 2004, 220, 27-35.

(5) Webb, J. R.; Bolaño, T. B.; Gunnoe, T. B. ChemSusChem 2011, 4, $37-49$

(6) Conley, B. L.; Tenn III, W. J.; Young, K. J. H.; Ganesh, S. K.; Meier, S. K.; Ziatdinov, V. R.; Mironov, O.; Oxgaard, J.; Gonzales, J.; Goddard III, W. A.; Periana, R. A. J. Mol. Catal. A: Chem. 2006, 251, $8-23$.

(7) Periana, R. A.; Bhalla, G.; Tenn III, W. J.; Young, K. J. H.; Liu, X. Y.; Mironov, O.; Jones, C. J.; Ziatdinov, V. R. J. Mol. Catal. A: Chem. 2004, 220, 7-25.

(8) Goldberg, K. I.; Goldman, A. S. Activation and Functionalization of $\mathrm{C}-\mathrm{H}$ Bonds; American Chemical Society: Washington, DC, 2004; Vol. 885 .

(9) Stahl, S. S.; Labinger, J. A.; Bercaw, J. E. Angew. Chem., Int. Ed. 1998, 37, 2180-2192.

(10) Jones, W. D. Science 2002, 295, 289-290.

(11) Fulton, J. R.; Holland, A. W.; Fox, D. J.; Bergman, R. G. Acc. Chem. Res. 2002, 35, 44-56.

(12) Shilov, A. E.; Shul'pin, G. B. Chem. Rev. 1997, 97, 2879-2932.

(13) Crabtree, R. H. J. Chem. Soc., Dalton Trans. 2001, 2437-2450.

(14) Jones, C. J.; Taube, D.; Ziatdinov, V. R.; Periana, R. A.; Nielson, R. J.; Oxgaard, J.; Goddard III, W. A. Angew. Chem., Int. Ed. 2004, 43, $4626-4629$.

(15) Muehlhofer, M.; Strassner, T.; Herrmann, W. A. Angew. Chem., Int. Ed. 2002, 41, 1745.

(16) Lersch, M.; Tilset, M. Chem. Rev. 2005, 105, 2471-2526.

(17) Theopold, K. H.; Gunay, A. Chem. Rev. 2010, 110, 1060-1081.

(18) Chen, M. S.; White, M. C. Science 2007, 318, 783-787.

(19) Que, J., L.; Ho, R. Y. N. Chem. Rev. 1996, 96, 2607-2624.

(20) Díaz-Requejo, M. M.; Belderraín, T. R.; Nicasio, M. C.; Trofimenko, S.; Pérez, P. J. J. Am. Chem. Soc. 2003, 125, 12078-12079.

(21) Badiei, Y. M.; Dinescu, A.; Dai, X.; Palomino, R. M.; Heinemann, F. W.; Cundari, T. R.; Warren, T. H. Angew. Chem., Int. Ed. 2008, 47, 9961-9964.

(22) Au, S.-M.; Huang, J.-S.; Yu, W.-Y.; Fung, W.-H.; Che, C.-M. J. Am. Chem. Soc. 1999, 121, 9120-9132.

(23) Doyle, M. P.; Duffy, R.; Ratnikov, M.; Zhou, L. Chem. Rev. 2010, 110, 704-724.

(24) Asensio, G.; Caballero, A.; Despagnet-Ayoub, E.; Díaz-Requejo, M. M.; Díaz-Rodríguez, A.; González-Núñez, M. E.; Mello, R.; Muñoz, B. K.; Ojo, W. S.; Etienne, M.; Pérez, P. J. Science 2011, 332, 835-838.

(25) Gol'dshleger, N. F.; Tyabin, M. B.; Shilov, A. E.; Shteinman, A. A. Zh. Fiz. Khim. (Engl. Transl.) 1969, 43, 1222.

(26) Bhalla, G.; Mironov, O.; Jones, C. J.; Tenn III, W. J.; Nakamura, S.; Periana, R. A. Handbook of $\mathrm{C}-\mathrm{H}$ Transformations; Wiley-VCH: 2005; Vol. 2, pp 529-542.

(27) Labinger, J. A.; Weinberg, D. R.; Bercaw, J. E. Organometallics 2007, 26, 167-172.

(28) Zhong, H. A.; Labinger, J. A.; Bercaw, J. E. J. Am. Chem. Soc. 2002, 124, 1378-1399.

(29) Conley, B. L.; Ganesh, S. K.; Gonzales, J. M.; Tenn III, W. J.; Young, K. J. H.; Oxgaard, J.; Goddard III, W. A.; Periana, R. A. J. Am. Chem. Soc. 2006, 128, 9018-9019.

(30) Tenn III, I., W. J.; Young, K. J. H.; Bhalla, G.; Oxgaard, J.; Goddard III, W. A.; Periana, R. A. J. Am. Chem. Soc. 2005, 127, 14172-14173.

(31) Feng, Y.; Lail, M.; Barakat, K. A.; Cundari, T. R.; Gunnoe, T. B.; Petersen, J. L. J. Am. Chem. Soc. 2005, 127, 14174-14175.

(32) Brown, S. N.; Mayer, J. M. J. Am. Chem. Soc. 1996, 118, 1211912133.

(33) Brown, S. N.; Mayer, J. M. Organometallics 1995, 14, 29512960.
(34) Koo, K. M.; Hillhouse, G. L.; Rheingold, A. L. Organometallics 1995, 14, 456-460.

(35) Matsunaga, P. T.; Hillhouse, G. L.; Rheingold, A. L. J. Am. Chem. Soc. 1993, 115, 2075-2077.

(36) Matsunaga, P. T.; Mavropoulos, J. C.; Hillhouse, G. L. Polyhedron $1995,14,175-185$.

(37) Alsters, P. L.; Teunissen, H. T.; Boersma, J.; Spek, A. L.; Vankoten, G. Organometallics 1993, 12, 4691-4696.

(38) Kamaraj, K.; Bandyopadhyay, D. Organometallics 1999, 18, $438-446$.

(39) AbuOmar, M. M.; Hansen, P. J.; Espenson, J. H. J. Am. Chem. Soc. 1996, 118, 4966-4974.

(40) Gonzales, J. M.; Distasio, R.; Periana, R. A.; Goddard III, W. A.; Oxgaard, J. J. Am. Chem. Soc. 2007, 129, 15794-15804.

(41) Periana, R. A.; Bischof, S. M.; Cheng, M. J.; Nielsen, R. J.; Gunnoe, T. B.; Goddard III, W. A. Organometallics 2011, 30, 20792082.

(42) Feng, Y.; Lail, M.; Foley, N. A.; Gunnoe, T. B.; Barakat, K. A.; Cundari, T. R; Petersen, J. L. J. Am. Chem. Soc. 2006, 128, 79827994.

(43) Tenn III, I., W. J.; Young, K. J. H.; Oxgaard, J.; Nielson, R. J.; Goddard III, W. A.; Periana, R. A. Organometallics 2006, 25, 51735175.

(44) Kloek, S. M.; Heinekey, D. M.; Goldberg, K. I. Angew. Chem., Int. Ed. 2007, 46, 4736-4738.

(45) Hanson, S. K.; Heinekey, D. M.; Goldberg, K. I. Organometallics 2008, 27, 1454-1463.

(46) Bercaw, J. E.; Hazari, N.; Labinger, J. A. Organometallics 2009, $28,5489-5492$.

(47) Cundari, T. R.; Grimes, T. V.; Gunnoe, T. B. J. Am. Chem. Soc. 2007, 129, 13172-13182.

(48) Ess, D. H.; Gunnoe, T. B.; Cundari, T. R.; Goddard III, W. A.; Periana, R. A. Organometallics 2010, 29, 6801-6815.

(49) Figg, T. M.; Cundari, T. R.; Gunnoe, T. G. Organometallics 2011, 30, 3779-3785.

(50) Frisch, M. J.; et al. Gaussian 09; Gaussian Inc.: Wallingford, CT, 2009.

(51) Lee, C.; Yang, W.; Parr, R. G. Phys. Rev., B 1988, 37, 785-789.

(52) Becke, A. D. J. Phys. Chem. 1988, 38, 3098.

(53) Stevens, W. J.; Basch, H.; Krauss, M. J. Chem. Phys. 1984, 81, 6026-6033.

(54) Cundari, T. R.; Stevens, W. J. J. Chem. Phys. 1993, 98, 5555.

(55) Stephens, P. J.; Devlin, F. J.; Chabalowski, C. F.; Frisch, M. J. J. Phys. Chem. 1994, 98, 11623-11627.

(56) Cossi, M.; Rega, N.; Scalmani, G.; Barone, V. J. Comput. Chem. 2003, 24, 669-681.

(57) Reyes, L.; Castro, M.; Cruz, J.; Rubio, M. J. Phys. Chem. A 2005, 109, 3383-3390.

(58) Reyes, L.; Alvarez-Idaboy, J. R; Mora-Diez, N. J. Phys. Org. Chem. 2009, 22, 643-649.

(59) Renz, M.; Meunier, B. Eur. J. Org. Chem. 1999, 737-750.

(60) Oxgaard, J.; Tenn III, I., W. J.; Nielson, R. J.; Periana, R. A.; Goddard III, W. A. Organometallics 2007, 26, 1565-1567.

(61) Webb, J. R.; Pierpont, A. W.; Munro-Leighton, C.; Gunnoe, T. B.; Cundari, T. R.; Boyle, P. D. J. Am. Chem. Soc. 2010, 132, 4520-4521.

(62) Fulmer, G. R.; Muller, R. P.; Kemp, R. A.; Goldberg, K. I. J. Am. Chem. Soc. 2009, 131, 1346. 